\title{
Are dayside long-period pulsations related to the cusp?
}

\author{
V. Pilipenko ${ }^{1}$, V. Belakhovsky ${ }^{2}$, M. J. Engebretson ${ }^{3}$, A. Kozlovsky ${ }^{4}$, and T. Yeoman $^{5}$ \\ ${ }^{1}$ Space Research Institute, Moscow, Russia \\ ${ }^{2}$ Polar Geophysical Institute, Apatity, Russia \\ ${ }^{3}$ Augsburg College, Minneapolis, MN, USA \\ ${ }^{4}$ Sodankyla Observatory, Oulu University Branch, Oulu, Finland \\ ${ }^{5}$ University of Leicester, Leicester, UK
}

Correspondence to: V. Pilipenko (pilipenk@augsburg.edu)

Received: 26 August 2014 - Revised: 8 February 2015 - Accepted: 6 March 2015 - Published: 24 March 2015

\begin{abstract}
We compare simultaneous observations of longperiod ultra-low-frequency (ULF) wave activity from a Svalbard/IMAGE fluxgate magnetometer latitudinal profile covering the expected cusp geomagnetic latitudes. Irregular Pulsations at Cusp Latitudes (IPCL) and narrowband Pc5 waves are found to be a ubiquitous element of ULF activity in the dayside high-latitude region. To identify the ionospheric projections of the cusp, we use the width of return signal of the Super Dual Auroral Radar Network (SuperDARN) radar covering the Svalbard archipelago, predictions of empirical cusp models, augmented whenever possible by Defense Meteorological Satellite Program (DMSP) identification of magnetospheric boundary domains. The meridional spatial structure of broadband dayside Pc5-6 pulsation spectral power has been found to have a localized latitudinal peak, not under the cusp proper as was previously thought, but several degrees southward from the equatorward cusp boundary. The earlier claims of the dayside monochromatic Pc5 wave association with the open-closed boundary also seems doubtful. Transient currents producing broadband Pc5-6 probably originate at the low-latitude boundary layer/central plasma sheet (LLBL/CPS) interface, though such identification with available DMSP data is not very precise. The occurrence of broadband Pc5-6 pulsations in the dayside boundary layers is a challenge to modelers because so far their mechanism has not been firmly identified.
\end{abstract}

Keywords. Ionosphere (ionosphere-magnetosphere interactions) - magnetospheric physics (magnetopause cusp and boundary layers; MHD waves and instabilities)

\section{Introduction}

The most intense wave activity in the ultra-low-frequency (ULF) frequency range (from fractions of millihertz to a few hertz) is persistently observed at high latitudes during daytime. Irregular long-period magnetic pulsations are observed almost every day over a wide period range (3-20 min) when a ground-based magnetic observatory happens to be within several hours from local noon (Olson, 1986; McHarg et al., 1995). These high-latitude disturbances were denoted as IPCL (Irregular Pulsations at Cusp Latitudes) in Bolshakova et al. (1988) and broadband Pc5 pulsations in Rostoker et al. (1972), McHarg and Olson (1992), Engebretson et al. (1995) and Posch et al. (1999). The issue of whether these pulsations are characteristic of some dayside boundary domain/boundary is still unresolved, though earlier many researchers suggested this type of ULF wave activity as a possible cusp (or the ionospheric projection of some magnetospheric dayside boundary layer) discriminant. So, widely used earlier terms "cusp-related pulsation" or IPCL are likely not adequate for correctly characterizing these events; the term "broadband dayside Pc5-6 activity" would probably be more adequate. The driver of these broadband dayside Pc56 pulsations has not been firmly established. These fluctuations were suggested to be triggered by solar wind variations (Friis-Christensen et al., 1988), sporadic reconnection (flux transfer events) (Bolshakova and Troitskaya, 1982; Lee and Lanzerotti, 1986; Lanzerotti and McLennan, 1988), shear instability at the reversal boundary of ionospheric convection associated with the LLBL (Clauer and Ridley, 1995; Clauer et al., 1997), or they could be a manifestation of the intermittency of turbulent solar wind flow (Kurazkovskaya and 
Klain, 2000). Broadband Pc5-6 pulsations could be a driving factor for the simultaneous quasi-monochromatic Pc5 pulsations observed at lower latitudes (Clauer et al., 1997; Engebretson et al., 1989). Indeed, at high geomagnetic latitudes, $\Phi \sim 80^{\circ}$, broadband Pc5-6 pulsations are the most common dayside irregular quasi-periodic disturbances. At the same time, at lower latitudes, $\Phi \sim 75^{\circ}$, intense series of monochromatic Pc5 waves with periods of 3-5 min are observed. The dramatic difference in their appearance is probably caused by the band-pass filtering due to field-line resonant response at lower latitudes to a high-latitude driver.

An increase in the intensity of dayside ULF wave activity over a wide frequency range, from Pc6/Pc5 to Pc3/Pi1 (Lepidi et al., 1996; Engebretson et al., 2006), is commonly associated with the cusp/cleft region. Early studies of dayside ULF activity at high latitudes gave hope that long-period irregular variations were supposedly closely associated with the cusp/cap interface, and thus could be used as a simple indicator of the dayside cusp position and the polar cap boundary (Troitskaya and Bolshakova, 1977, 1988; Troitskaya, 1985; Bolshakova et al., 1988; Dunlop et al., 1994). However, further studies of high-latitude broadband wave activity on the dayside showed that it cannot simply be associated with cusp proximity, but, instead, showed a coordinated time dependence across several hours of local time (Engebretson et al., 1995). Attempts to find a cause for these widespread temporal variations in the solar wind, interplanetary magnetic field (IMF), or substorm injections have so far been fruitless.

The appearance of monochromatic Pc5 pulsations during the morning hours through local noon at stations at latitudes below $80^{\circ}$ was associated with resonant standing Alfvén waves on the last closed field lines, near the dayside magnetopause (Ables et al., 1998; Lanzerotti et al., 1999). The band of enhanced wave power evident in dynamic spectrograms had the form of an "arch", with the frequency increasing from $\sim 1$ to $\sim 4 \mathrm{mHz}$ during a several-hour interval from early morning toward local noon, then slowly decreasing until it disappeared in early afternoon. The distinction between broadband and band-limited wave activity was suggested to characterize the location of the open-closed field line boundary (OCB). For synoptic monitoring of the OCB, Urban et al. (2011) used a meridional array of Antarctic magnetometers, and retrieved a nominal Pc5 mode with periods $T \sim 3-$ $9 \mathrm{~min}$ and long-period modes with $T>10 \mathrm{~min}$. They assumed that isolated Pc5 presence corresponds to closed dayside field lines, whereas high power in both bands indicated that a close magnetotail field line was being sampled. During quiet periods they observed at the South Pole $\left(\Phi \sim 74^{\circ}\right) \mathrm{U}$ shaped power spectra, indicating the dominance of long periods during nighttime and Pc5 dominance during daytime.

So far, the spatial correspondence between a particular dayside boundary domain and ULF activity peak has not been reliably established. It is not yet known which magnetospheric boundary region is responsible for long-period dayside ULF waves: mantle, LLBL, cusp, region I/region II current systems, or something else. In most previous studies of long-period pulsations there had been no available information about the actual instantaneous location of the cusp, or any other dayside boundary domain, so conclusions about the association of ULF wave activity with the cusp were made on the basis of the nominal statistical cusp location. Three data sources have emerged to provide information on cusp location. First, particle measurements made by low-orbiting spacecraft (e.g, Defense Meteorological Satellite Program (DMSP), NOAA) provide direct determination of the ionospheric projections of various magnetospheric boundary domains and hence provide the benchmark for other observations. However, their usage is restricted as they only make snapshot observations of the particle precipitation boundaries in each polar region every $\sim 100 \mathrm{~min}$. Second, the Doppler spectral width boundary at about $200 \mathrm{~m} \mathrm{~s}^{-1}$ has been shown to be a good proxy of the ionospheric projection of the cusp (Baker et al., 1995). Comparison of the cusp boundary identification with the Super Dual Auroral Radar Network (SuperDARN) data and with DMSP particle detector showed good correspondence between those techniques (Cai et al., 2009; Baker et al., 1990). Third, ground optical observations of the red $(630.0 \mathrm{~nm})$ and green $(557.7 \mathrm{~nm})$ line aurorae around noon can give very relevant information on precipitation boundaries and the location of the cusp (e.g., Milan et al., 1999; Sandholt et al., 2002); however, this is possible only during polar night (in December and early January at the Svalbard location) and with clear sky conditions. For the present study we have no suitable optical data.

In order to obtain additional clues about the mechanisms of high-latitude Pc5-6 waves, in this paper we compare this wave activity in the dayside high-latitude region recorded by the IMAGE and Greenland arrays of magnetometers with simultaneous monitoring of the cusp location derived from SuperDARN radar observations. Whenever possible, observations have been augmented with DMSP data on the ionospheric projections of magnetospheric boundary domains. Some implications of the observational results are discussed.

\section{Observational facilities and data analysis technique}

Fluxgate magnetometers (10 s sampling rate) are deployed at Svalbard and throughout Scandinavia in a closely spaced configuration. In Greenland fluxgate magnetometers are deployed along the west and east coasts. From these arrays of instruments it is possible to form a latitudinal profile along the $\Lambda \sim 110^{\circ}$ geomagnetic meridian across Svalbard (noon $\sim$ 09:00 UT, $\mathrm{LT}=\mathrm{UT}+3$ ), NRD-NAL-LYR-HOR-HOPBJN-SOR (shown in Fig. 1 and Table 1).

To identify the ionospheric projections of the cusp, we use data from the SuperDARN HF radar located in Hankasalmi, Finland. This radar system provides high timeresolution measurements ( $120 \mathrm{~s}$ in routine operations) of the 
Table 1. List of stations used in the study. Corrected geomagnetic coordinates and UT of local magnetic noon (MLT) have been computed for an altitude of $100 \mathrm{~km}$ using the NSSDC web facility (http://nssdc.gsfc.nasa.gov/space/cgm/cgm.html).

\begin{tabular}{lcrrrrr}
\hline \multicolumn{7}{c}{$110^{\circ}$ combined IMAGE - Greenland east coast array. } \\
\hline Station & Station code & Geog. lat. & Geog. long. & Geom. lat. & Geom. long. & UT of MLT noon \\
\hline Nord & NRD & 81.60 & 343.33 & 80.9 & 105.8 & $09: 17$ \\
Ny ̊̊lesund & NAL & 78.93 & 11.95 & 76.3 & 110.6 & $08: 56$ \\
Longyearbyen & LYR & 78.20 & 15.83 & 75.3 & 111.7 & $08: 50$ \\
Barentsburg & BAB & 78.07 & 14.23 & 75.3 & 110.4 & $08: 57$ \\
Hornsund & HOR & 76.97 & 15.47 & 74.2 & 109.1 & $09: 01$ \\
Hopen Island & HOP & 76.51 & 25.10 & 72.9 & 116.5 & $08: 29$ \\
Bear Island & BJN & 74.50 & 19.20 & 71.4 & 108.1 & $08: 56$ \\
Sørøya & SOR & 70.54 & 22.22 & 67.2 & 106.7 & $08: 48$ \\
\hline
\end{tabular}

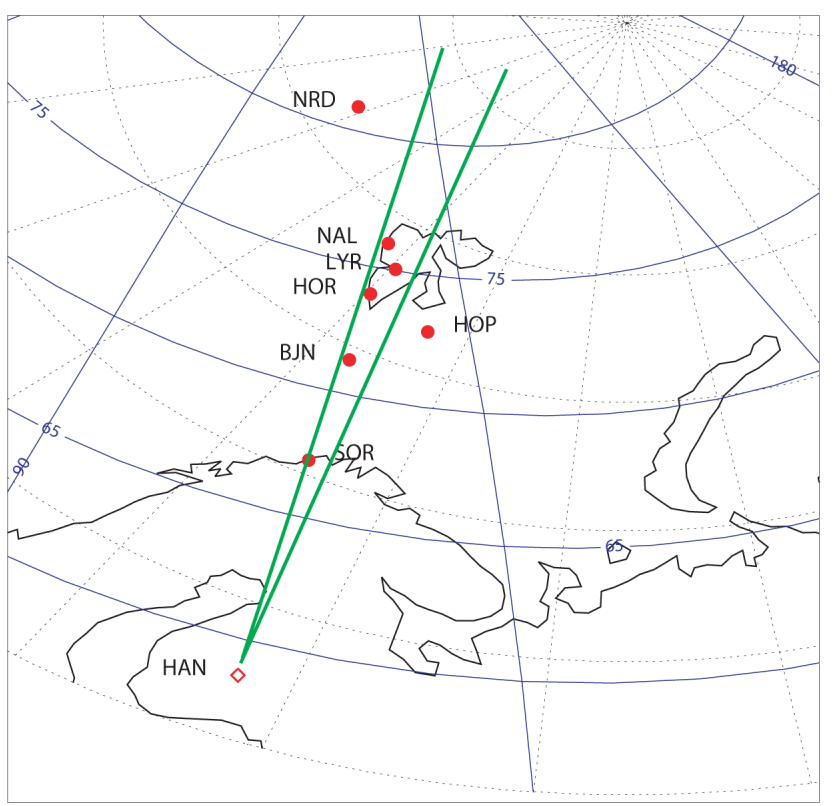

Figure 1. Map of the combined IMAGE and Greenland magnetometer array. Beam no. 9 (green lines) of SuperDARN highfrequency (HF) radar in Hankasalmi (indicated by the open diamond) covers the Svalbard archipelago.

ionospheric flow vectors with a spatial resolution on the order of $50 \mathrm{~km}$. Beam no. 9 covers the Svalbard magnetometers. The SuperDARN radar technique has been successfully used to identify the relative location of dayside high-latitude wave activity in the Pc3 band (Yeoman et al., 2012).

Statistical models driven by the IMF/SW parameters nowcast the cusp boundaries with correlation coefficients up to 0.8 . The highest correlation is provided by the "half-wave rectifier" model and the Newell et al. (2006) model. The latter will be used to additionally estimate the cusp location. According to this model, the equatorward cusp boundary is predicted to be $\sim 78^{\circ}$ when IMF $B_{z} \sim 0$, and should shift equatorward when IMF $B_{z}<0$.

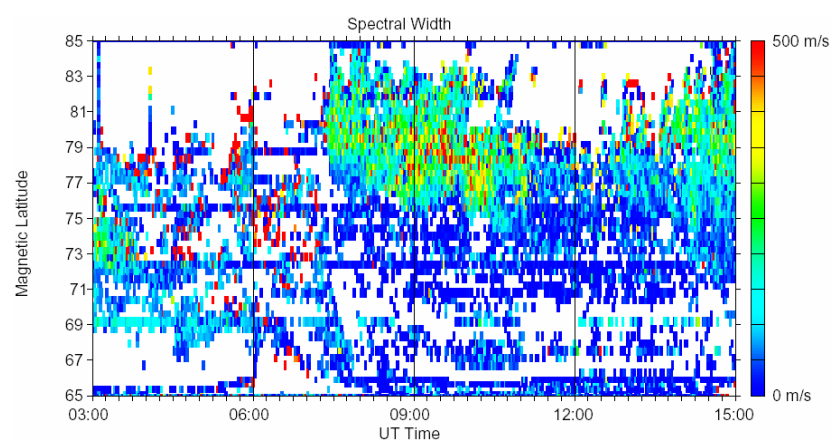

Figure 2. A magnetic local time-magnetic latitude snapshot of the line-of-sight Doppler velocity and spectral width from the Hankasalmi SuperDARN radar from 03:00 to 15:00 UT on 4 January 2002 .

To categorize the ionospheric projection of the magnetospheric boundary layers, the low-altitude $(\sim 800 \mathrm{~km})$ DMSP charged-particle precipitation characteristics have been used (Newell and Meng, 1988). The automated dayside region identification program (http://sd-www.jhuapl.edu/ Aurora/dayside/dayside.html) distinguishes magnetospheric regions through the characteristics of precipitating electrons and ions (in the $30 \mathrm{eV}$ to $30 \mathrm{keV}$ range).

\section{Typical events}

From radar campaigns in 2001-2002, we have identified $>10 \mathrm{ULF}$ events when it was possible to determine the cusp location from the radar data. We consider only daytime hours to avoid the contamination of ULF activity by disturbances related to nighttime substorms. Here we present two typical events.

\subsection{January 2002 (day 004)}

According to HAN radar data, both the ionospheric velocity pattern and the spectral width of radio signal returns indicate 


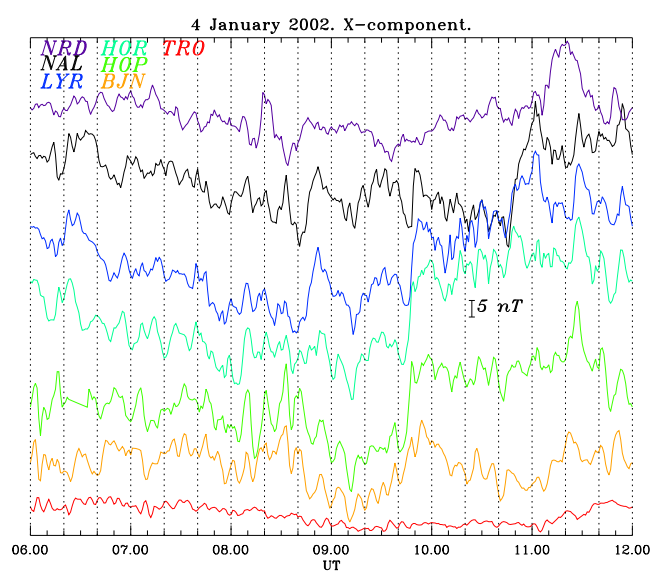

Figure 3. Magnetograms of $X$ component magnetic variations along the IMAGE + Greenland $100^{\circ}$ magnetic longitude profile from 06:00 to 12:00 UT on 4 January 2002.

that the cusp equatorward boundary was observed on this day from $\sim 07: 30$ to $\sim 11: 00$ UT. According to the OMNI database the mean IMF and solar wind parameters for the period 07:00-10:00 UT were: $V \sim 330 \mathrm{~km} \mathrm{~s}^{-1}, N \sim 6 \mathrm{~cm}^{-3}$, $B_{y} \sim-5 \mathrm{nT}$, and $B_{z}$ was varying between +1 and $-4 \mathrm{nT}$. During this period, the boundary was on average around $76^{\circ}$ (Fig. 2); however, it was moving north and south within this interval following the variability (fluctuations) of the IMF parameters (not shown here). For an averaged $B_{z}=-3 \mathrm{nT}$, the statistical model predicts the cusp boundary location to have been at $\sim 76^{\circ}$.

Along the latitudinal magnetometer array, quasi-periodic variations with timescales from $\sim 7$ to $\sim 15$ min were observed with peak-to-peak amplitudes larger than $10 \mathrm{nT}$ (Fig. 3). These variations are most evident in the $X$ component from $\sim 08: 00$ to $\sim 10: 00 \mathrm{UT}$ at HOP and BJN.

Fourier spectra for the time interval 07:00-10:00 UT show the dominance of frequencies $\sim 0.6$ and $\sim 1.5 \mathrm{mHz}$ (not shown). Visual inspection of waveforms demonstrates that they were time shifted between different latitudes, indicating an apparent poleward propagation. This result has been validated with cross-correlation analysis for the period 07:0010:00 UT using NAL as a reference station. Indeed, the time lag $\Delta t$ of the cross-correlation function $R(\Delta t)$ varied from $\sim 10 \mathrm{~s}$ for LYR to $\sim 60 \mathrm{~s}$ for BJN (not shown).

The latitudinal distribution of $X$ component spectral power for the time period 07:00-10:00 UT integrated in the 0.4$3.0 \mathrm{mHz}$ band shows a maximum around $73-74^{\circ}$ (HOPHOR) (Fig. 4). Thus, the ULF maximum is shifted $\sim 2^{\circ}$ equatorward from the equatorward cusp boundary (shown by the vertical dashed line). The vertical $Z$ component, on the other hand, has a local minimum in the region of maximal $X$ component power, and increases towards higher latitudes.

The superposition of all DMSP-identified boundary domain projections from available satellite tracks and station
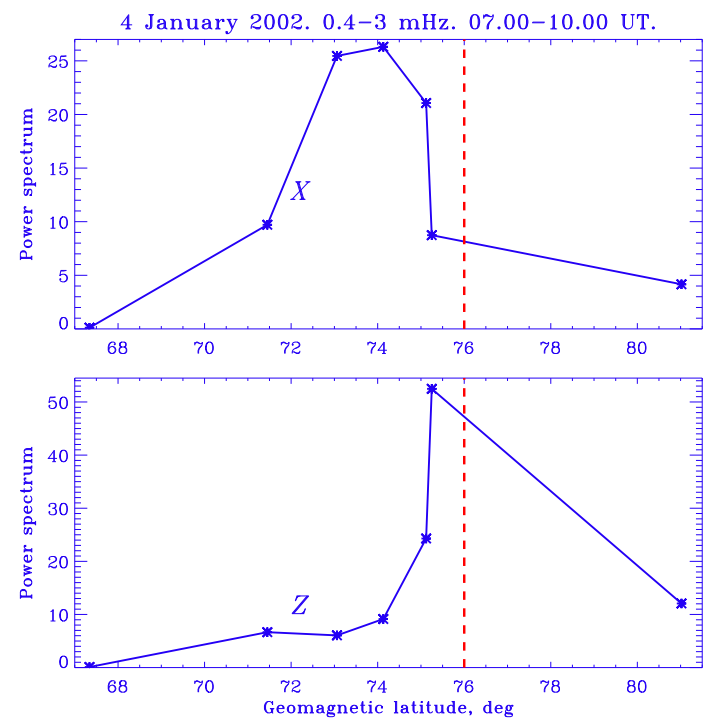

Figure 4. The latitudinal distribution of band-integrated (0.4$1.7 \mathrm{mHz}$ ) hourly spectral power in the IPCL band for the time interval 06:00 to 12:00 UT 4 January 2002. The vertical dotted line (red) indicates the equatorward cusp boundary location.

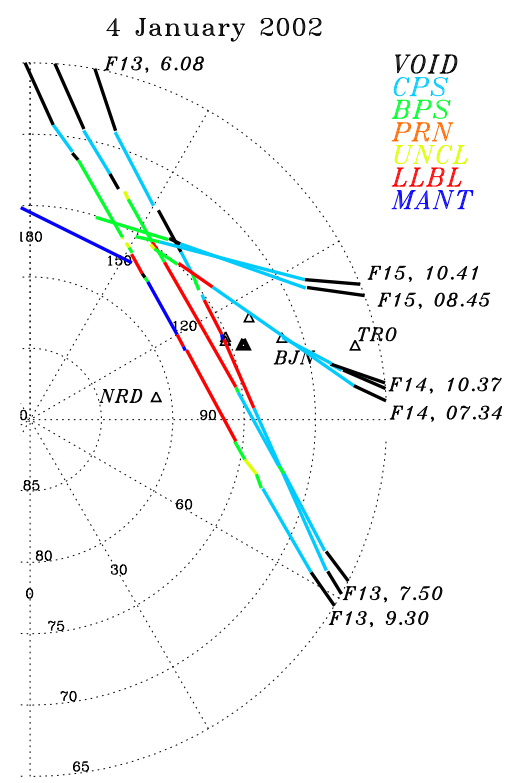

Figure 5. The superposition of the DMSP-identified boundary domain ionospheric projections in the dayside hemisphere and station locations during the period of cusp observations by radar, from 07:00 to 11:00 UT (in geomagnetic coordinates). The station with maximal ULF power is marked by a solid triangle.

locations during the period of cusp observations by radar, i.e., 07:00-10:00 UT, is shown in Fig. 5. This comparison shows that the latitudinal maximum of the broadband Pc5-6 power (highlighted by the solid triangle) corresponds to the projection of the LLBL. 


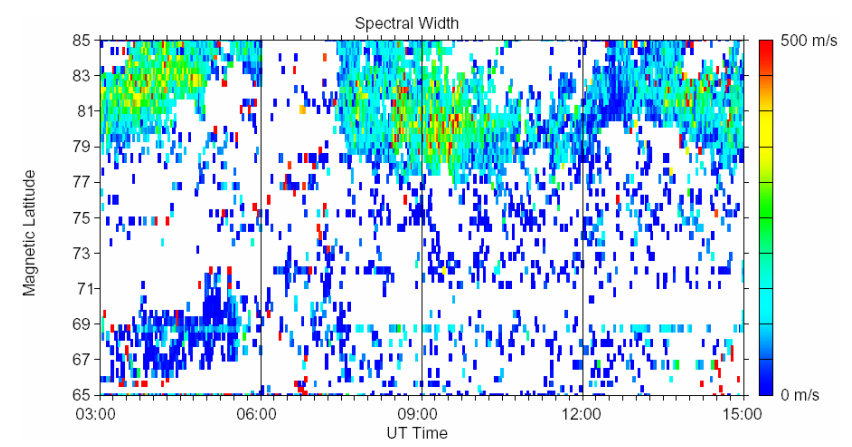

Figure 6. A magnetic local time-magnetic latitude snapshot of lineof-sight Doppler velocity and spectral width from the Hankasalmi SuperDARN radar from 03:00 to 15:00 UT 9 December 2001.

\subsection{December 2001 (day 343)}

SuperDARN radar identified a slow equatorward drift of the equatorward cusp boundary near $\sim 78^{\circ}$ for the period from $\sim$ 07:30 to $\sim 11: 00 \mathrm{UT}$ (Fig. 6). According to the OMNI database, from 07:00 to 10:00 UT the IMF $B_{z}$ component was slightly negative $(\sim 0 /-2 \mathrm{nT})$, and the $B_{y}$ component gradually changed from -4 to $0 \mathrm{nT}$. The solar wind velocity was $\sim 370 \mathrm{~km} \mathrm{~s}^{-1}$ and the plasma density $\sim 2-3 \mathrm{~m}^{-3}$. The statistical position of the equatorward cusp boundary estimated from the model (Newell et al., 2006) corresponds to the SuperDARN observations.

Intense irregular pulsations were observed along the Svalbard array from $\sim 06: 30$ to $\sim$ 09:30 UT (Fig. 7). In their broadband spectra, the frequencies $\sim 0.4 \mathrm{mHz}$ and $\sim 1.2 \mathrm{mHz}$ are highlighted (not shown). Visual inspection of $X$ component magnetograms indicates an apparent poleward propagation. This conclusion is supported by a crosscorrelation analysis for the period 07:00-10:00 UT using NAL as a reference station, which shows that the time lag $\Delta t$ of the cross-correlation function $R(\Delta t)$ varied from $\sim 50 \mathrm{~s}$ for LYR to $\sim 330 \mathrm{~s}$ for BJN.

The latitudinal distribution of band-integrated (0.4$3 \mathrm{mHz}) X$ component spectral power (Fig. 8, top panel) had its maximum around $74^{\circ}$ (HOR). This maximum is $\sim 4^{\circ}$ equatorward from the cusp boundary. At the same time, the latitudinal distribution of the $Z$ component power (Fig. 8, bottom panel) had a local minimum nearly in the same region, $\sim 73^{\circ}$, and two maxima away from it. Visual inspection of waveforms shows that the $Z$ component variations in the maxima (NAL-LYR and BJN) were roughly in anti-phase to each other (not shown).

The superposition of the DMSP-identified boundary domain projections and station locations during the period of Pc5-6 pulsation occurrence, i.e., 06:00-10:00 UT (Fig. 9), shows that the latitudinal maximum of the broadband dayside Pc5-6 power was inside the CPS.

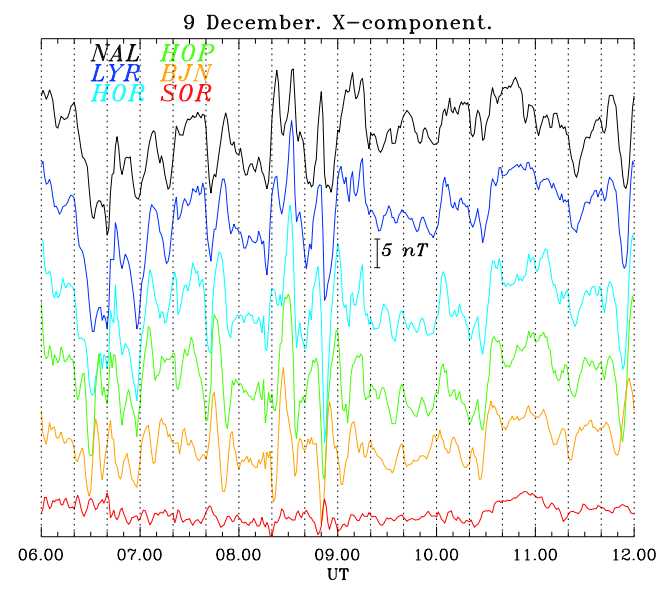

Figure 7. Magnetograms of the $X$ component along the IMAGE profile from 06:00 to 12:00 UT on 9 December 2001. Data from NRD are missing.

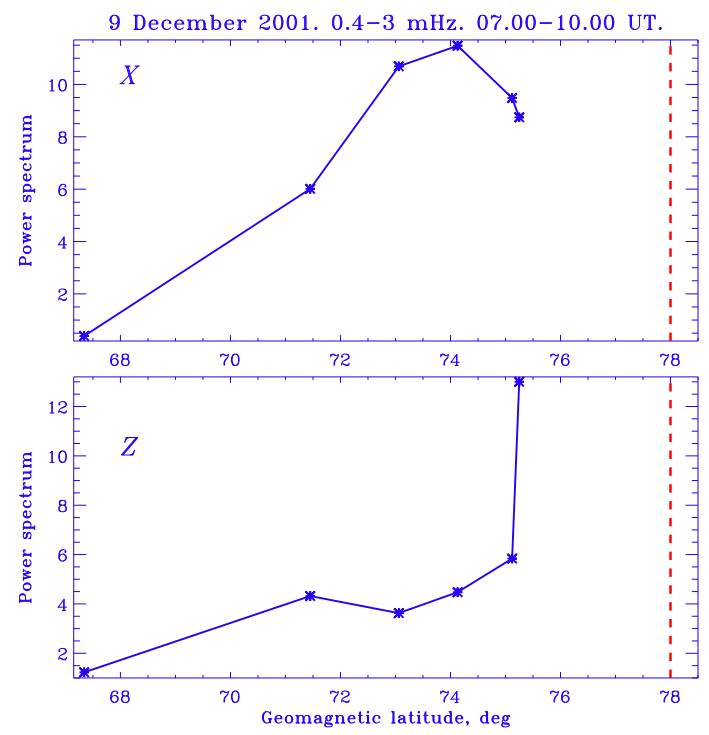

Figure 8. The CGM latitudinal distribution of band-integrated (0.7$6.0 \mathrm{mHz}$ ) hourly spectral power for the time interval 05:00 to 10:00 UT 9 December 2001. The vertical dotted line (red) indicates the equatorward cusp boundary location, identified from $\mathrm{Su}$ perDARN data.

\section{Statistical latitudinal distribution}

The normalized statistical distribution of $X$ component broadband Pc5-6 spectral power in the $0.4-3.0 \mathrm{mHz}$ band for the eight most intense ULF events observed along the $\Lambda \sim 110^{\circ}$ latitudinal profile with respect to the distance from the cusp boundary, identified for each event from SuperDARN observations, is shown in Fig. 10. Table 2 summarized the interplanetary parameters and the cusp location information during each event. It shows that all events were observed during low-to-moderate solar wind velocities of 310- 
Table 2. Interplanetary parameters and cusp location during selected events.

\begin{tabular}{llrrrrrr}
\hline Date & UT & $\begin{array}{r}\text { Vsw, } \\
\mathrm{km} \mathrm{s}^{-1}\end{array}$ & $\begin{array}{r}N, \\
\mathrm{~cm}^{-3}\end{array}$ & $\begin{array}{r}B_{z}, \\
\mathrm{nT}\end{array}$ & $\begin{array}{r}B_{y}, \\
\mathrm{nT}\end{array}$ & $\begin{array}{r}\text { SuperDARN } \\
\text { cusp (Lat) }\end{array}$ & $\begin{array}{r}\text { ULF-max } \\
\text { (Lat) }\end{array}$ \\
\hline 2 Feb 2001 & $06.30-09.30$ & 420 & 4 & $0 ;+2$ & 2 & 76 & 73.1 \\
7 Dec 2001 & $07.00-10.00$ & 460 & 3 & $5 ; 0$ & -5 & 78 & 74.1 \\
25 Jan 2011 & $08.00-11.00$ & 320 & 6 & -3 & $0 ;-2$ & 75 & 73.1 \\
19 Dec 2009 & $09.00-12.00$ & 420 & 4 & $0 ;-2$ & -3 & 77 & 73.1 \\
19 Feb 2010 & $07.00-10.00$ & 460 & $1-2$ & $2 ;-4$ & 6 & 78 & 73.1 \\
26 Jan 2011 & $07.30-10.30$ & 310 & 8 & $2 ;-1$ & $-2 ; 0$ & 77 & 74.1 \\
8 Feb 2011 & $07.00-10.00$ & 430 & $3-4$ & $-2 ; 0$ & -2 & 76 & 74.1 \\
23 Jan 2010 & $07.00-10.00$ & 360 & 5 & -2 & $2 ; 0$ & 76 & 74.1 \\
\hline
\end{tabular}

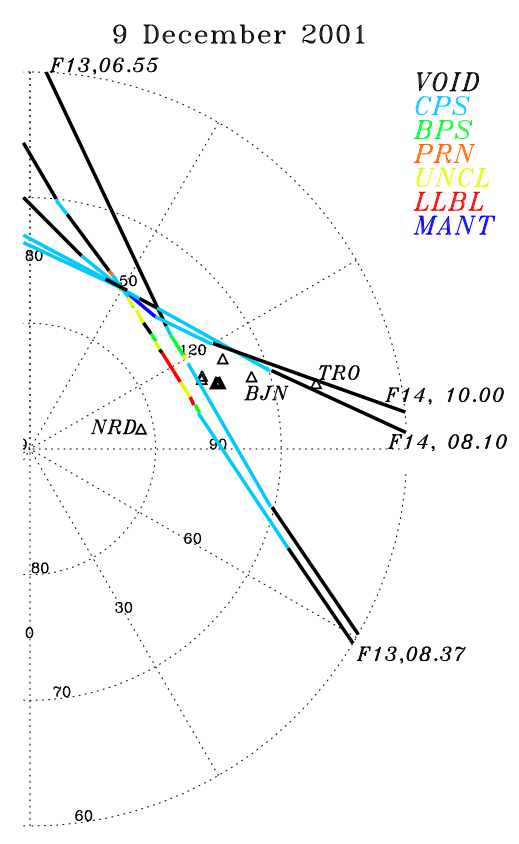

Figure 9. The superposition of the DMSP-identified boundary domain projections in the dayside hemisphere and station locations during the period of cusp observations by radar, from 07:00 to 10:00 UT 9 December 2001 (in polar geomagnetic coordinates). The station with maximal ULF power is highlighted by a solid triangle.

$460 \mathrm{~km} \mathrm{~s}^{-1}$. Though the individual distributions are widely dispersed, the summary plot evidently shows that broadband dayside Pc5-6 $X$ component power is shifted by $1^{\circ}-5^{\circ}$ from the cusp equatorward boundary.

\section{Discussion}

Long-period broadband pulsations in the nominal Pc5-6 band have been known to be a persistent feature in the ULF activity at dayside high latitudes. At high latitudes during daytime, a mixture of broadband Pc5-6 and narrowband Pc5 is observed, though there is no well-established criterion to separate these phenomena. In the events under consideration a regular transition from irregular broadband pulsations at high latitudes to more intense and monochromatic Pc5 pulsations at lower latitudes can be seen, similar to Engebretson et al. (2002). These events indicate that quasi-monochromatic Pc5 and broadband pulsations are not separate wave phenomena, but the manifestations of the same wave process, whereas the difference in their appearance is related to resonant amplification deeper into the magnetosphere, probably on closed dipole-like field lines. It is natural to suppose that broadband Pc5-6 corresponds to a source, and Pc5 pulsations are its resonant response (Clauer et al., 1997). However, there is no one-to-one correspondence between their occurrence: sometimes one can see broadband Pc5-6 without a Pc5 response at lower latitudes, and sometimes one can see monochromatic Pc5 without broadband Pc5-6 at higher latitudes (Kleimenova et al., 1985, 1998). Thus, it is still uncertain whether the excitation mechanisms of these pulsations are firmly coupled or not. It is likely that there are a variety of source mechanisms for these pulsations and until the driving conditions are sorted properly, the situation will seem confusing.

While narrowband Pc5 pulsations are evidently produced by the resonant response of closed field lines inside the magnetosphere, it is tempting to associate broadband dayside Pc5-6 pulsations with disturbances at the magnetosphere boundary. In this case, on the ground the "epicenter" of their activity is to be observed near the ionospheric projection of the equatorward boundary. However, our examination of the local latitudinal distribution of band-integrated ULF power in the Pc5-6 range with respect to the equatorward cusp boundary has shown that in fact "cusp pulsations" are not related to the cusp proper. The peak of their power distribution is shifted several degrees southward from the equatorward cusp boundary, identified from simultaneous SuperDARN observations. Moreover, the longitudinal extent of pulsations observed on the ground is wider than the cusp. Commonly, pulsations along the Svalbard array that begin earlier than the time that the cusp is detected by radar. It is worth mentioning the parallel story about high-latitude dayside Pc3 waves. 


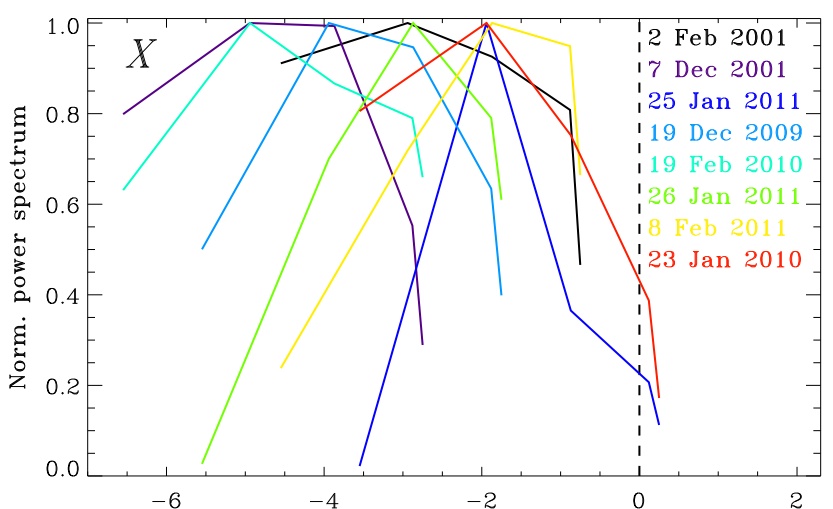

Figure 10. The statistical distribution of IPCL spectral power ( $X$ component) for 8 events along the NAL-LYR-HOR-HOPBJN-SOR profile with respect to the distance from the equatorward cusp boundary. All the spectra have been normalized by their maximal value.

They were also at first thought to be closely associated with the cusp, but as Yeoman et al. (2012) showed, they instead maximize $\sim 2^{\circ}$ equatorward of it. This justifies the usage of more adequate term "broadband dayside Pc5-6 activity" instead of "cusp-related pulsation" or IPCL. Broadband dayside Pc5-6 activity is probably comprised of multiple generation mechanisms, so our conclusions may be invalid for other classes of high-latitude ULF pulsations. In general, the physics of these pulsations will remain confusing until the conditions under which they are produced are sorted properly.

A related question is the location of the observed maximum of pulsation activity with respect to the OCB. Indeed, Lockwood (1997) pointed out that the OCB can be located equatorward of the cusp. Such a precipitation regime is identified as the open LLBL adjacent the cusp (Newell and Meng, 1998). According to the Lockwood (1997) model newly open field lines are characterized by the disappearance of CPS electrons giving rise to a void regime between the CPS and the LLBL (open field lines), and this model obtained experimental support for cases of southward IMF (Sandholt and Farrugia, 2002; Sandholt et al., 2002, 2004). Statistically, the open LLBL has sizes on the order of $1 \mathrm{~h}$ in MLT and $1^{\circ}$ in MLat (Newell et al., 2004). The largest separation in MLat between the spectral width boundary and the OCB is expected in intervals of $B_{z}$-dominated $\left(\left|B_{z} / B_{y}\right|>1 ; B_{z}<0\right)$ IMF orientations (Lockwood, 1997). However, in the present study all the cases are characterized by $\left|B_{z} / B_{y}\right| \leq 1$, so we may hardly expect a substantial $\left(>1^{\circ}\right)$ width of open LLBL for $3 \mathrm{~h}$. Because the maximum of pulsation power was well more than $2^{\circ}$, poleward of the spectral width boundary, we believe that the maximum was predominantly on closed magnetic field lines.

Here it is necessary to mention that identification of the cusp from ground radar data is not a straightforward prob- lem. The broadening of spectral lines in SuperDARN radar backscatter is frequently considered as a signature of the cusp (e.g., Chisham et al., 2005), though in some cases, especially during northward or near-zero IMF $B_{z}$ (Safargaleev et al., 2008), a large spectral width was observed on both open and closed field lines. The region of increased spectral width may also include closed LLBL or other turbulent precipitation regions, which has been shown by Villain et al. (2002). Moreover, Kozlovsky et al. (2011) have shown that spectral width increase up to $200 \mathrm{~m} \mathrm{~s}^{-1}$ can be due to the gradient drift instability cascade in the regions of enhanced electric field (up to $50 \mathrm{mV} \mathrm{m}^{-1}$ ). Such electric fields are indeed observed equatorward of the cusp on closed field lines (see e.g., Figs. 4 and 8 in Sandholt and Farrugia (2007). Thus, the latitude of equatorial cusp boundary derived from the spectral width data may be underestimated. This is one more argument for the location of pulsation maxima well equatorward of the cusp, on closed magnetic field lines.

Additionally, we tried to use data from the SuperDARN radar in Goose Bay to check the cusp location above the Greenland west coast magnetometer profile. However, the cusp signatures at this radar were not very clear. The difference in the cusp detection by SuperDARN radars in Hankasalmi and Goose Bay is probably related to their different beam orientation to the cusp. Additionally, we tried to use particle precipitation data from DMSP satellites, which are a reliable means to obtain the cusp location (Safargaleev et al., 2008). Though for all the analyzed events the DMSP tracks were rather far from the meridian under examination, a tendency was observed that maximal ULF activity was situated around the CPS/LLBL interface, though sometimes shifted into the region of the ionospheric projection of the CPS or LLBL. This is consistent with the Clauer and Ridley (1995) case study of Pc6 ( $20 \mathrm{~min})$ pulsation observed with maximum amplitude at the convection reversal boundary determined by incoherent scatter radar. It was reliably shown that the convection reversal boundary is in the region of LLBL particle precipitation measured by DMSP satellites. Certainly not all dayside ULF waves result from this source, but this is certainly one definite source of the broadband Pc56 pulsations linked to a specific boundary.

The poleward Pc5-6 propagation observed near cusp latitudes, earlier noticed by Olson (1989), indicates that ground ULF variations cannot simply be attributed to a quasistationary oscillatory current system. The latitudinal phase delay can be caused by several mechanisms:

a. peculiar frequency-dependent amplitude-phase spatial structure formed in the region of Alfvén field line resonance. Such structure is typical for narrowband Pc5 pulsations and gives evidence that their excitation mechanism is related to the resonance of standing Alfvén oscillations. Another feature of this resonant structure is the maximum in latitudinal distribution on the ground of the vertical $Z$ component amplitude coinciding with 
the maximum of the horizontal N-S component (Southwood and Hughes, 1978; Pilipenko et al., 2000a). This feature is not seen in the observed latitudinal structure of the broadband Pc5-6 power; the opposite, in fact, was observed: in the region of maximal $H$ component power, a local minimum of $Z$ component power was observed. Thus, broadband dayside Pc5-6 cannot be associated with field line Alfvén resonance;

b. latitude-dependent time-of-flight propagation from the equatorial plane towards the polar ionosphere. In this case, the $Z$ component amplitude has a minimum and phase reversal in the region of the N-S component amplitude maximum (Pilipenko et al., 2000b). The observed broadband Pc5-6 latitudinal structure with a localized maximum of coherent $\mathrm{N}-\mathrm{S}$ components and outof-phase vertical components beyond this maximum probably corresponds to the variations produced by fluctuations of E-W extended currents transported by latitude-dependent field-aligned currents from the magnetosphere.

It may be supposed that broadband Pc5-6 activity is the ground manifestation of turbulent flow around the magnetosphere. Moreover, the clear dependence of the intensity of long-period dayside pulsations at high latitudes on the solar wind velocity (Engebretson et al., 1995) favors this suggestion. However, one aspect of the scenario must be understood. A turbulent magnetosheath plasma flow should provide a maximal ground response around the ionospheric projection of the magnetopause, whereas the periodicity of Pc56 oscillations may be imposed by the very extended nondipole field line length. However, our study has found that the epicenter of Pc5-6 power is located inside the magnetosphere, probably around the CPS/LLBL interface or inside the auroral oval. Therefore, it still has to be comprehended why the response to the magnetosheath turbulence driving is displaced from the magnetosheath/magnetosphere interface. Moreover, dayside narrowband Pc5 pulsations, located even deeper in the magnetosphere than broadband Pc56 , can hardly be associated with oscillations of last closed field lines, as had been suggested by Lanzerotti et al. (1999) and Urban et al. (2011). It is worth noticing that in the same period scale as Pc5-6 pulsations, there is a class of impulsive/transient disturbances, traveling convection vortices (TCVs), which are commonly observed in the prenoon sector. Comparison of TCV events with the particle precipitation boundaries obtained from low-altitude DMSP satellite measurements indicated that TCVs mapped to the CPS/boundary plasma sheet (BPS) boundary well within the magnetosphere (Yahnin et al., 1997), contrary to the belief that TCV-related currents originated at the magnetopause. However, they did not suggest a mechanism for TCV location.

We are not aware of detailed in situ observations of a magnetospheric counterpart of persistent dayside high-latitude ULF activity in the Pc5-6 band. Only in one event, when the magnetosphere was strongly compressed and a number of geosynchronous satellites happened to be in the LLBL, Takahashi et al. (1991) observed 5-10 min irregular compressional oscillations. Moreover, we suppose that prospects to find such a counterpart in the equatorial magnetosphere are not very promising because broadband dayside ULF wave power over a range of longitudes across local noon, near the footpoint of the cusp/cleft/LLBL are predominantly nonconjugate (Engebretson et al., 2002).

As another possibility, it may be suggested that broadband Pc5-6 are related to quasi-periodic fluctuations of fieldaligned currents or to irregular particle precipitation. Indeed, at dayside high latitudes there are several regions of fieldaligned currents, strongly dependent on the IMF components $B_{z}$ and $B_{y}$. Region I corresponds to the equatorward boundary of the polar cusp, where currents flow into the ionosphere in the morning side and from the ionosphere in the afternoon side. Region III (or NBZ) is concentrated at the poleward border of the cusp, with current direction opposite to that in region I. The upward field-aligned currents are transported by precipitating electrons, while downward currents are due to upward-moving thermal ionospheric electrons. It is interesting that in nearly half of the events considered here, the onset of the cusp-related ULF pulsations is marked by an isolated bay-like disturbance, in accordance with earlier observations by Olson (1986), which may be a signature of a large-scale current system. However, we are unable to verify a possible correspondence between ULF wave power and global magnetosphere-ionosphere current systems because of a lack of reliable monitors of the field-aligned current system above the magnetometer array (e.g., low-orbiting satellites with magnetometers onboard). Nonetheless, we do not believe that high-latitude broadband geomagnetic pulsations can be attributed to the fluctuating energetic electron precipitation. Such precipitation would barely produce a coherent latitudinally phase-shifted magnetic response on the ground, which observations have clearly revealed.

\section{Conclusions}

Dayside high-latitude ULF pulsations will still continue to be difficult to understand until they are sorted into proper classes. Examination of the local latitudinal structure of highlatitude pulsations by magnetometers at Svalbard and Greenland, covering near-cusp latitudes, has shown the occurrence of a localized peak in the distribution of broadband dayside Pc5-6 power about $3^{\circ} \pm 2^{\circ}$ southward from the equatorward cusp boundary, but not under the cusp proper as was suggested in early studies. For the dayside high-latitude ULF events examined in this paper, broadband Pc5-6 pulsations, and moreover narrowband dayside Pc5 waves, are unlikely to be associated with oscillations of last closed field lines. The broadband dayside Pc5-6 pulsations are supposed to be the ground response to transient currents, probably originating 
at the LLBL/CPS interface, though such identification with available DMSP data is not very precise. The obtained result imposes important limitations on possible mechanisms of high-latitude ULF variations. In general, dayside highlatitude ULF waves still remains a zone of confusion.

Acknowledgements. This work was supported by grant MK4210.2015.5 of the President of the Russian Federation (V. Belakhovsky), grant 14-05-00588 from the Russian Fund for Fundamental Research (V. Pilipenko, T. Yeoman), and US NSF grant ATM-0827903 (M. J. Engebretson). The facility in Ny Ålesund is maintained by the Norwegian Polar Institute (www.npolar.no); Longyearbyen is supported by the Kjell Henriksen Observatory (http://kho.unis.no); Hornsund is maintained by the Polish Institute of Geophysics, the IMAGE magnetometer array is maintained by Finnish Meteorological Institute (www.geo.fmi.fi/image), and the Greenland magnetometer array is operated by the Danish Space Research Institute (www.space.dtu.dk). The DMSP particle detectors were designed by D. Hardy of AFRL, and data obtained from JHU/APL (http://sd-www.jhuapl.edu/Aurora). We thank D. Hardy, F. Rich, and P. Newell for its use. We thank all participants of the SuperDARN project (www.superdarn.ac.uk), who collected data used in this study. The constructive criticism of the reviewers is appreciated.

Topical Editor L. Blomberg thanks two anonymous referees for their help in evaluating this paper.

\section{References}

Ables, S. T., Fraser, B. J., Waters, C. L., Neudegg, D. A., and Morris, R. J.: Monitoring cusp/cleft topology using Pc5 ULF waves, Geophys. Res. Lett., 25, 1507-1510, 1998.

Baker, K. B., Greenwald, R. A., Ruohoniemi, J. M., Dunedey, J. R., Pinnock, M., Newell, P. T., Greenspan, M. E., and Meng, C.I.: Simultaneous HF-radar and DMSP observations of the cusp, Geophys. Res. Lett., 17, 1869-1872, 1990.

Baker, K. B., Dudeney, J. R., Greenwald, R. A., Pinnock, M., Newell, P. T., Rodger, A. S., Mattin, N., and Meng, C.-I.: HF radar signatures of the cusp and low-latitude boundary layer, J. Geophys. Res., 100, 7671-7695, doi:10.1029/94JA01481, 1995.

Bolshakova, O. V. and Troitskaya, V. A.: Pulsed reconnection as a possible source of IPLC pulsations, Geomagn. Aeronomy (English Translation), 22, 723-725, 1982.

Bolshakova, O. V., Kleimenova, N. G., and Kurazhkovskaya, N. A.: Polar cap dynamics using the observations of long period geomagnetic pulsations, Geomagn. Aeronomy, 28, 661-664, 1988.

Cai, H. T., McCrea, I. W., Dunlop, M. W., Davies, J. A., Bogdanova, Y. V., Pitout, F., Milan, S. E., Lockwood, M., and Ma, S. Y.: Cusp observations during a sequence of fast IMF BZ reversals, Ann. Geophys., 27, 2721-2737, doi:10.5194/angeo-272721-2009, 2009.

Chisham, G., Freeman, M. P., Sotirelis, T., Greenwald, R. A., Lester, M., and Villain, J.-P.: A statistical comparison of SuperDARN spectral width boundaries and DMSP particle precipitation boundaries in the morning sector ionosphere, Ann. Geophys., 23, 733-743, doi:10.5194/angeo-23-733-2005, 2005.
Clauer, C. R. and Ridley, A. J.: Ionospheric observations of magnetospheric boundary layer waves on August 4, 1991, J. Geophys. Res., 100, 21873-21884, 1995.

Clauer, C. R., Ridley, A. J., Sitar, R. J., Singer, H., Rodger, A. S., Friis-Christensen, E., and Papitashvili, V. O.: Field line resonant pulsations associated with a strong dayside ionospheric shear convection flow reversal, J. Geophys. Res., 102, 45854596, 1997.

Dunlop, I. S., Menk, F. W., Hansen, H. J., Fraser, B. J., and Morris, R. J.: A multistation study of long period geomagnetic pulsations at cusp and boundary layer latitudes, J. Atmos. Terr. Phys., 56, 667-672, 1994.

Engebretson, M. J., Anderson, B. J., Cahill, L. J., Arnoldy, R. L., Newell, P. T., Zanetti, C.-J., and Potemra, T. A.: A multi-point case study of high-latitude ULF pulsations, J. Geophys. Res., 94 17143-17160, 1989.

Engebretson, M. J., Hughes, W. J., Alford, J. L., Zesta, E., Cahill, L. J., Arnoldy, R. L., and Reeves, G. D.: Magnetometer array for cusp and cleft studies observations of the spatial extent of broadband ULF magnetic pulsations at cusp/cleft latitudes. J. Geophys. Res., 100, 19371-19386, 1995.

Engebretson, M. J., Posch, J. L., and Hughes, W. J.: Nonconjugate ULF wave power observed by ground magnetometers in the northern and southern dayside cusp/cleft/LLBL regions, in: "Earth's Low-Latitude Boundary Layer", edited by: Newell, P. and Onsager, T. G., Geophys. Monograph 133, AGU, Washington D.C., 223-230, 2002.

Engebretson, M. J., Posch, J. L., Pilipenko, V. A., and Chugunova, O. M.: Ground based observations of ULF waves at high latitudes, in: Magnetospheric ULF Waves: Synthesis and New Directions, edited by: Takahashi, K., Chi, P. J., Denton, R. E., Lysak R. L., Geophys. Monograph 169, AGU, Washington DC, 137156, 2006.

Friis-Christensen, E., Vennerstrom, S., Clauer, C. R., and McHenry, M. A.: Irregular magnetic pulsations in the polar cleft caused by travelling ionospheric convection vortices, Adv. Space Res., 8, 311-314, 1988.

Kleimenova, N. G., Bolshakova, O. V., Troitskaya, V. A., and FriisChristensen, E.: Two types of long period geomagnetic pulsations near equator border of dayside polar cusp, Geomagn. Aeronomy, 25, 163-166, 1985.

Kleimenova, N. G., Kozyreva, O. V., Bitterly, J., and Bitterly, M.: Long-period $(T \sim 8-10 \mathrm{~min})$ geomagnetic pulsations at high latitudes, Geomagn. Aeronomy, 38, 38-48, 1998.

Kozlovsky, A., Shalimov, S., Koustov, A. V., Lukianova, R., and Turunen, T.: Dependence of spectral width of ionospheric F region HF echoes on electric field, J. Geophys. Res., 116, A07302, doi:10.1029/2011JA016804, 2011.

Kurazkovskaya, N. A. and Klain, B. I.: Peculiar features of burst series of long-period irregular IPCL-type geomagnetic pulsations in the vicinity of the dayside cusp, Geomagn. Aeronomy International, 2, 129-135, 2000.

Lanzerotti, L. J. and MacLennan, C. G.: Hydromagnetic waves associated with possible flux transfer events, Astrophys. Space Sc., 144, 279-290, 1988.

Lanzerotti, L. J., Shono, A., Fukunishi, H., and Maclennan, C. G.: Long-period hydromagnetic waves at very high geomagnetic latitudes, J. Geophys. Res., 104, 28423-28435, 1999. 
Lee, L. C. and Lanzerotti, L. J.: A mechanism for the generation of cusp region hydromagnetic waves, J. Geophys. Res., 93, 75787585, 1986.

Lepidi, S., Villante, U., Vellante, M., Palangio, P., and Meloni, A.: High resolution geomagnetic field observations at Terra Nova Bay, Antarctica, Annali di Geofizica, 33, 519-528, 1996.

Lockwood, M.: Relationship of dayside auroral precipitations to the open-closed separatrix and the pattern of convective flow, J. Geophys. Res., 102, 17475-17487, 1997.

McHarg, M. G. and Olson, J. V.: Correlated optical and ULF magnetic observations of the winter cusp-boundary layer system, J. Geophys. Res., 19, 817-820, 1992.

McHarg, M. G., Olson, J. V., and Newell, P. T.: ULF cusp pulsations: diurnal variations and interplanetary magnetic field correlations with ground-based observations, J. Geophys. Res., 100, 19729-19742, 1995.

Milan, S. E., Lester, M., Cowley, S. W. H., Moen, J., Sandholt, P. E., and Owen, C. J.: Meridian-scanning photometer, coherent HF radar, and magnetometer observations of the cusp: a case study, Ann. Geophys., 17, 159-172, doi:10.1007/s00585-999-0159-5, 1999.

Newell, P. T. and Meng, C.-I.: The cusp and the cleft/boundary layer: low-altitude identifications and statistical local time variation, J. Geophys. Res., 93, 14549-145556, 1988.

Newell, P. T. and Meng, C.-I.: Open and closed low latitude boundary layer, in: Polar Cap Boundary Phenomena, edited by: Moen, J., Egeland, A., and Lockwood, M., 91-101, Kluwer Acad., Norwell, Mass. 1998.

Newell, P. T., Ruohoniemi, J. M., and Meng, C.-I.: Maps of precipitation by source region, binned by IMF, with inertial convection streamlines, J. Geophys. Res., 109, A10206, doi:10.1029/2004JA010499, 2004.

Newell, P. T., Sotirelis, T., Liou, K., Meng, C.-I., and Rich, F. J.: Cusp latitude and the optimal solar wind coupling function, J. Geophys. Res., 111, A09207, doi:10.1029/2006JA011731, 2006.

Olson, J. V.: ULF signatures of the polar cusp, J. Geophys. Res., 91, 10055-10062, 1986.

Olson, J. V.: Poleward propagation of pulsations near the cusp, Planet. Space Sci., 37, 775-781, 1989.

Pilipenko, V., Vellante, M., and Fedorov, E.: Distortion of the ULF wave spatial structure upon transmission through the ionosphere, J. Geophys. Res., 105, 21225-21236, 2000a.

Pilipenko, V. A., Fedorov, E. N., Engebretson, M. J., Papitashvili, V. O., and Watermann, J.: Poleward progressing quasi-periodic disturbances at cusp latitudes: The role of wave processes, J. Geophys. Res., 105, 27569-27588, 2000b.

Posch, J. L., Engebretson, M. J., Weatherwax, A. T., Detrick, D., Hughes, W. J., and Maclennan, C. G.: Characteristics of broadband ULF magnetic pulsations at conjugate cusp latitude stations, J. Geophys. Res., 104, 311-331, 1999.

Rostoker, G., Samson, J. C., and Higuchi, Y.: Occurrence of Pc4,5 micropulsation activity at the polar cusp, J. Geophys. Res., 77, 4700-4706, 1972.

Safargaleev, V., Kozlovsky, A., Sergienko, T., Yeoman, T. K., Uspensky, M., Wright, D. M., Nilsson, H., Turunen, T., and Kotikov, A.: Optical, radar, and magnetic observations of magnetosheath plasma capture during a positive IMF $B_{z}$ impulse, Ann. Geophys., 26, 517-531, doi:10.5194/angeo-26-517-2008, 2008.
Sandholt, P. E. and Farrugia, C. J.: Monitoring magnetosheathmagnetosphere interconnection topology from the aurora, Ann. Geophys., 20, 629-637, doi:10.5194/angeo-20-629-2002, 2002.

Sandholt, P. E. and Farrugia, C. J.: Poleward moving auroral forms (PMAFs) revisited: responses of aurorae, plasma convection and Birkeland currents in the pre- and postnoon sectors under positive and negative IMF $B_{y}$ conditions, Ann. Geophys., 25, 16291652, doi:10.5194/angeo-25-1629-2007, 2007.

Sandholt, P. E., Denig, W. F., Farrugia, C. J., Lybekk, B., and Trondsen, E.: Auroral structure at the cusp equatorward boundary: Relationship with the electron edge of low-latitude boundary layer precipitation, J. Geophys. Res., 107, 1235, doi:10.1029/2001JA005081, 2002.

Sandholt, P. E., Farrugia, C. J., and Denig, W. F.: Dayside aurora and the role of IMF $\left|B_{y}\right| /\left|B_{z}\right|$ : detailed morphology and response to magnetopause reconnection, Ann. Geophys., 22, 613628, doi:10.5194/angeo-22-613-2004, 2004.

Southwood, D. J. and Hughes, W. J.: Source induced vertical components in geomagnetic pulsation signals, Planet. Space Sci., 26, 715-720, 1978.

Takahashi, K., Sibeck, D. G., Newell, P. T., and Spence, H. E.: ULF waves in the low-latitude boundary layer and their relationship to magnetospheric pulsations: A multisatellite observation, J. Geophys. Res., 96, 9503-9519, 1991.

Troitskaya, V. A.: ULF waves investigations in the dayside cusps, Adv. Space Res., 5, 219-228, 1985.

Troitskaya, V. A. and Bolshakova, O. V.: Diurnal latitude variation of the location of the dayside cusp, Planet. Space Sci., 25, 11671169, 1977.

Troitskaya, V. A. and Bolshakova, O. V.: Diagnostics of the magnetosphere using multipoint measurements of ULF waves, Adv. Space Res., 8, 413-425, 1988.

Villain, J.-P., André, R., Pinnock, M., Greenwald, R. A., and Hanuise, C.: A Statistical study of the Doppler spectral width of high-latitude ionospheric F-region echoes recorded with SuperDARN coherent HF radars, Ann. Geophys., 20, 1769-1781, doi:10.5194/angeo-20-1769-2002, 2002.

Urban, K. D., Gerrard, A. J., Bhattacharya, Y., Ridley, A. J., Lanzerotti, L. J., and Weatherwax, A. T.: Quiet time observations of the open-closed boundary prior to the CIRinduced storm of 9 August 2008, Space Weather, 9, S11001, doi:10.1029/2011SW000688, 2011.

Yahnin, A. G., Vorobjev, V. G., Bosinger, T., Rasinkangas, R., Sibeck, D. G., and Newell, P. T.: On the source region of traveling convection vortices, Geophys. Res. Lett., 24, 237-240, 1997.

Yeoman, T. K., Wright, D. M., Engebretson, M. J., Lessard, M. R., Pilipenko, V. A., and Kim, H.: Upstream-generated Pc3 ULF wave signatures observed near the Earth's cusp, J. Geophys. Res., 117, A03202, doi:10.1029/2011JA017327, 2012. 